\title{
Intraperitoneal neutrophils activated by KRAS-induced ovarian cancer exert antitumor effects by modulating adaptive immunity
}

\author{
MITSUYO YOSHIDA $^{1}$, AYUMI TAGUCHI ${ }^{1}$, KEI KAWANA ${ }^{2}$, JURI OGISHIMA $^{1}$, KATSUYUKI ADACHI ${ }^{1}$, \\ AKIRA KAWATA $^{1}$, HIROE NAKAMURA ${ }^{1}$, MASAKAZU SATO ${ }^{1}$, ASAHA FUJIMOTO ${ }^{1}$, TOMOKO INOUE ${ }^{1}$, \\ KENSUKE TOMIO $^{1}$, MAYUYO MORI ${ }^{1}$, TAKESHI NAGAMATSU ${ }^{1}$, TAKAHIDE ARIMOTO ${ }^{1}$, KAORI KOGA ${ }^{1}$, \\ OSAMU WADA HIRAIKE ${ }^{1}$, KATSUTOSHI ODA ${ }^{1}$, TOHRU KIYONO ${ }^{3}$, YUTAKA OSUGA ${ }^{1}$ and TOMOYUKI FUJII ${ }^{1}$ \\ ${ }^{1}$ Department of Obstetrics and Gynecology, Graduate School of Medicine, The University of Tokyo, Bunkyo-ku, \\ Tokyo 113-8655; ${ }^{2}$ Department of Obstetrics and Gynecology, Nihon University School of Medicine, Itabashi-ku, \\ Tokyo 173-8610; ${ }^{3}$ Division of Virology, National Cancer Center Research Institute, Chuo-ku, Tokyo 104-0045, Japan
}

Received April 16,2018; Accepted July 4, 2018

DOI: 10.3892/ijo.2018.4504

\begin{abstract}
Increased neutrophil counts are a hallmark of a poor prognosis for cancer. We previously reported that KRAS promoted tumorigenesis and increased neutrophil counts in a mouse peritoneal cancer model. In the current study, we evaluated the role of increased neutrophils in cancer progression, as well as their influence on the intraperitoneal microenvironment. A mouse peritoneal cancer model was established using the KRAS-transduced mouse ovarian cancer cell line, ID8-KRAS. Neutrophil function was assessed by neutrophil depletion in ID8-KRAS mice. Neutrophil depletion markedly accelerated tumor formation; this was accompanied by an increase in interleukin- 6 concentrations in ascites. Neutrophil depletion significantly decreased the amount of local and systemic $\mathrm{CD} 8^{+} \mathrm{T}$ cells, while increasing the amount of local $\mathrm{CD}^{+} \mathrm{T}$ cells, accompanied by an increased amount of monocytic myeloid-derived suppressor cells (M-MDSCs) and regulatory T cells (Tregs) $(\mathrm{P}<0.05)$. The roles of peritoneal neutrophils (PENs) in $\mathrm{CD}^{+} \mathrm{T}$ cell activation were assessed in vitro. PENs of ID8-KRAS mice had a strong potential to enhance $T$ cell proliferation with a higher expression of the $\mathrm{T}$ cell costimulatory molecules OX40 ligand (OX40L) and 4-1BB ligand (4-1BBL), as compared with peripheral blood neutrophils (PBNs). These findings suggest that neutrophils recruited into the KRAS-induced tumor microenvironment
\end{abstract}

Correspondence to: Dr Ayumi Taguchi, Department of Obstetrics and Gynecology, Graduate School of Medicine, The University of Tokyo, 7-3-1 Hongo, Bunkyo-ku, Tokyo 113-8655, Japan E-mail: aytaguchi-tky@umin.ac.jp

Dr Kei Kawana, Department of Obstetrics and Gynecology, Nihon University School of Medicine, 30-1 Otaniguchi Uemachi, Itabashi-ku, Tokyo 173-8610, Japan

E-mail:kkawana-tky@umin.org

Key words: tumor microenvironment, tumor-associated neutrophils, T cells, costimulatory molecules, KRAS
(TME) have antitumor properties with the potential to modulate the numbers of M-MDSCs and Tregs and activate CD8 ${ }^{+}$ $\mathrm{T}$ cells through $\mathrm{T}$ cell costimulatory molecules.

\section{Introduction}

Increased neutrophil counts can sometimes predict a poor prognosis among patients with advanced cancers (1-3). Pan-cancer analysis performed by Templeton et al aided in the identification of polymorphonuclear leukocyte signaling as the most potent predictor of a poor prognosis (4). Increased neutrophil/lymphocyte $(\mathrm{N} / \mathrm{L})$ ratios have recently been attracting interest as a suitable prognostic marker for cancer patients $(4,5)$. Several reports have indicated that increased $\mathrm{N} / \mathrm{L}$ ratios are a marker of a poor prognosis and a weak response to chemotherapy among patients with ovarian cancer $(6,7)$. Although a number of studies have demonstrated the significance of increased neutrophil counts as a prognostic marker, an in-depth analysis has not yet been performed regarding its role in cancer progression, at least to the best of our knowledge.

Oncogenes are known to promote cell proliferation and prevent apoptosis in malignant cells. Although the association between oncogenes and tumor microenvironment (TME) modifications has not yet been sufficiently elucidated, recent studies have revealed that several oncogenes are associated with TME modulation $(8,9)$. KRAS is a frequently mutated oncogene in cancer. In a previous study, we established a KRAS-transduced mouse ovarian cancer cell line, ID8-KRAS, and demonstrated that the oncogene KRAS promoted tumorigenesis and aggravated cancer-induced inflammation, accompanied by an increased number of neutrophils in ascites (8). RAS is considered to promote cancer progression by sustaining proliferation, metabolic reprogramming, anti-apoptosis, and remodeling of the TME $(10,11)$. RAS followed by the activation of RAS-GTP and PI3K/AKT signaling may upregulate nuclear factor (NF)- $\kappa \mathrm{B}$ activity and lead to an inflammatory microenvironment (12). Similarly, several oncogenes may be associated with severe inflammation accompanied by an increased number of neutrophils. 
Although neutrophils have been regarded as a protumor marker, the role of tumor-associated neutrophils (TANs) in cancer progression has only recently become a focus area (13). There are two types of TANs: An interferon (IFN)- $\beta$-induced antitumor type (14) and a transforming growth factor (TGF)$\beta$-induced protumor type (15). The majority of studies have focused on the protumor properties of neutrophils and have associated neutrophils with a poor prognosis $(1,16,17)$. Recent findings have revealed that TANs exert antitumor effects in several cancer types through the stimulation of $\mathrm{T}$ cell activity $(17,18)$. However, the role of neutrophils in the oncogene-induced TME has not yet been elucidated.

In the KRAS-transduced ovarian cancer model, a marked increase in the number of neutrophils was observed; however, it is still unclear whether the increased number of neutrophils exerts a pro-tumor or antitumor effect in this model. Therefore, in this study, we investigated the role of recruited neutrophils in KRAS-induced ovarian cancer progression, as well as their influence on the intraperitoneal microenvironment.

\section{Materials and methods}

Cell lines and establishment of oncogene-transduced ID8 cells. We established oncogene-transduced mouse ovarian cancer cell lines by transducing KRAS into the mouse ovarian epithelial immortalized cell line, ID8, which was established from C57BL/6 mice (8). The ID8 cells were a kindly gift from Dr Kathy Roby, Department of Anatomy and Cell Biology, University of Kansas Medical Center (Kansas City, KS, USA). An oncogenic mutant form of human KRAS $\left(\mathrm{KRAS}^{\mathrm{G12}}{ }^{\mathrm{V}}\right)$ was recombined into pDEST-CLXSN to generate pCLXSN$\mathrm{KRAS}^{\mathrm{G} 12 \mathrm{~V}}$. Retrovirus packaging was performed as previously described (19). ID8-KRAS cells were established by infection of the LXSN-KRAS ${ }^{\mathrm{G} 12 \mathrm{~V}}$ virus at a multiplicity of infection of 1, followed by G418 selection at a concentration of $800 \mu \mathrm{g} / \mathrm{ml}$ for 1 week.

Mouse model. The ID8 and ID8-KRAS cells were cultured in Dulbecco's modified Eagle's medium (DMEM; Wako, Tokyo, Japan, 043-30085) containing 10\% FBS, $100 \mathrm{U} / \mathrm{ml}$ penicillin, $0.1 \mathrm{mg} / \mathrm{ml}$ streptomycin, and $0.25 \mathrm{~g} / \mathrm{ml}$ amphotericin $\mathrm{B}$. The ID8 and ID8-KRAS cells $\left(2 \times 10^{6}\right)$ suspended in $1,000 \mu \mathrm{l}$ DMEM were injected into the peritoneal cavities of 8 -week-old female C57/BL6 mice as previously described (8). The mice were obtained from Japan SLC and weighed 18-20 g. The animals were maintained at room temperature in a humiditycontrolled room with a $12 \mathrm{~h}$-light/12 h-dark cycle and were provided sterilized solid food and water ad libidum during the entire experimental period. Mice were sacrificed to minimize suffering when moribund behaviors were observed. In all cases, tissue collection procedures were initiated after animals had been euthanized by isoflurane overdose; mice were placed into a chamber filled with the vapor of the anesthetic isoflurane until respiration ceased (within $2 \mathrm{~min}$ ) (20). For the mouse survival analysis, mice were sacrificed when their body weight (BW) exceeded $23 \mathrm{~g}$ after inoculation as in our previous study (8), we confirmed that that approximately $5 \mathrm{ml}$ of ascites were accumulated with the formation of dissemination when the $\mathrm{BW}$ reached $23 \mathrm{~g}$. BW and ascites weight were assessed at the time of sacrifice. The total number of mice used in this study was 115 as follows: Experiment of the in vitro effects of neutrophils on CD8 T cell activation, 32 mice (no cancer mice, $\mathrm{n}=16$; ID8 mice, $\mathrm{n}=8$; ID8-KRAS mice, $\mathrm{n}=8$ ); experiment of $\mathrm{T}$ cell costimulatory molecules on neutrophils, 83 mice (CD80: no cancer, $\mathrm{n}=8$; ID8, $\mathrm{n}=5$; ID8-KRAS, $\mathrm{n}=7$; CD86: no cancer, $\mathrm{n}=6$; ID8, $\mathrm{n}=6$; ID8-KRAS, $\mathrm{n}=5$; 4-1BBL: no cancer, $\mathrm{n}=11$; ID8, $\mathrm{n}=5$; ID8-KRAS, $\mathrm{n}=7$; OX40L: no cancer, $\mathrm{n}=10$; ID8, $n=5$; ID8-KRAS, $n=8$ ).

Neutrophil depletion. Neutrophils were depleted using antiLy6G mAb (mouse) (Nimp-R14, AdipoGen Life Sciences, San Diego, CA, USA, AG-20B-0043-C100). This mAb has been reported to selectively deplete neutrophils in vivo $(21,22)$. The mice were injected intraperitoneally with $250 \mu \mathrm{g}$ antiLy6G mAb or matched isotype (rat IgG2b isotype control, Bio X Cell, West Lebanon, NH, USA, BE0090) in $0.5 \mathrm{ml}$ of PBS or with PBS alone every 3 days by the following two medication methods: Method A, from day 7 after inoculation of ID8-KRAS cells. Mice were sacrificed when their body weight exceeded $23 \mathrm{~g}$ (isotype, $\mathrm{n}=8$; and anti-Ly6G, $\mathrm{n}=9$ ). Method B, from day 10 after inoculation of ID8-KRAS cells. Mice were sacrificed on day 16 (isotype, $n=15$; and anti-Ly6G, $\mathrm{n}=16$ ). As a control, we used mice with no cancer which were not injected with any substance $(\operatorname{method} A, n=6$; method $B$, $\mathrm{n}=6)$.

Isolation of myelocyte peritoneal ascites. Mice were peritoneally inoculated with ID8-KRAS cells by the described medication described above in method B. Following the injection of $3 \mathrm{ml}$ of PBS, peritoneal myelocytes were recovered from peritoneal cavities of no cancer mice $(n=6)$ and ID8-KRAS mice treated with anti-Ly6G or isotype mAb. Peritoneal myelocytes were centrifuged at $300 \mathrm{x} g$ at room temperature for $5 \mathrm{~min}$. Red blood cells were removed by RBC lysed.

Isolation of neutrophils from blood and peritoneal ascites. After euthanized by isoflurane overdose, peritoneal ascites and approximately $1.5 \mathrm{ml}$ of blood by cardiac puncture were obtained from ID8 and ID8-KRAS mice. Neutrophils were isolated from the collected peritoneal ascites and blood using a magnetic cell sorting kit (Neutrophil Isolation kit, MACS KK; Miltenyi Biotec, Cologne, Germany) according to the manufacturer's instructions.

Isolation of lymphocytes from ascites and splenocytes. Mice were peritoneally inoculated with ID8-KRAS cells by the described medication method B. Peritoneal cells were obtained from peritoneal cavities of no cancer mice and ID8-KRAS mice treated with anti-Ly6G or isotype $\mathrm{mAb}$ after injection of $3 \mathrm{ml}$ of PBS. Splenocytes were prepared as follows: spleens obtained from no cancer mice and ID8-KRAS mice treated with anti-Ly6G or isotype $\mathrm{mAb}$ were homogenized between glass slides, RBC lysed, washed twice, and filtered with $100 \mu \mathrm{m}$ filter. Peritoneal cells and splenocytes were centrifuged $(300 \mathrm{x}$ g, $15 \mathrm{~min})$ to pellet them. The pellet was resuspended in $3 \mathrm{ml}$ of PBS and then layered onto a discontinuous Percoll gradient (44\%/70\%; Percoll, GE Healthcare, Chicago, IL, USA) followed by centrifugation at $400 \mathrm{xg}$ for $18 \mathrm{~min}$. The band between the 
Table I. Antibodies used in flow cytometry.

Antibody (clone, company, cat. no.)

Isotype (clone, company, cat. no.)

FITC-anti-mouse CD45 (B3821F4A/N901/UCHT1,

Beckman Coulter, Tokyo, Japan, CO6607071)

FITC-rat IgG, 2b, k isotype (eBRG1,

FITC-anti-mouse c-mesenchymal-epithelial transition

eBioscience, 11-4031-82)

(eBioclone7, eBioscience, Tokyo, Japan, 11-8854-80)

FITC-rat IgG1, k isotype (eBRG1,

eBioscience, 11-4301-82)

FITC-anti-mouse CD80 (16-10A1,

BioLegend, Tokyo, Japan, 104705)

FITC-Arm Hamster, IgG isotype

FITC-anti-mouse CD86 (GL1,

BioLegend, 105005)

(eBio299Arm, eBioscience, 11-4888-81)

PE-anti-mouse 4-1BB ligand (TKS-1,

FITC-rat IgG, 2b, k isotype (eB149/10H5, eBioscience, 11-4031-82)

BioLegend, 107105)

PE-mouse IgG, 2a, $\mathrm{k}$ isotype

(MOPC-173, BioLegend, 400211)

FITC-anti-mouse CD11b (M1/70,

eBioscience, 11-0122-85)

APC-anti-mouse Ly6G (RB6-8C5,

eBioscience, 17-5931-82)

FITC-rat IgG, 2b, k isotype (eBRG1, eBioscience, 11-4031-82)

APC-Rat, IgG, 2a, $\mathrm{k}$ isotype (eBR2a,

PE-anti-mouse Ly6G (RB6-8C5, eBioscience, 17-4321-81)

eBioscience, 12-5931-82)

PE-mouse IgG, 2a, k isotype

(MOPC-173, BioLegend, 40021)

APC-anti-mouse Ly6C (HK1.4,

APC-Rat, IgG, 2c, $\mathrm{k}$ isotype (RTK4174,

BioLegend, 128015)

BioLegend, 400713)

PE-Cyanine5-anti-mouse F4/80 (BM8,

PE-Cyanine5-Rat, IgG, 2a, $\mathrm{k}$ isotype

BioLegend, 123111)

(eBR2a, eBioscience, 35-4321-80)

FITC-anti-mouse CD8a

(53-6.7, eBioscience, 11-0081-81)

FITC-Rat, IgG, 2a, k isotype (eBR2a,

eBioscience, 11-4321-82)

PE-Cyanine5-anti-mouse CD3e

(145-2C11, eBioscience, 15-0031-82)

PE-Cyanine5-Arm Hamster, IgG isotype (eBio299Arm, eBioscience, 15-4888-82)

APC-anti-mouse CD4 (RM4-5,

APC-Rat, IgG, 2a, k isotype

eBioscience, 17-0042-81)

(eBR2a, BioLegend, 400512)

FITC-anti-mouse CD25 (PC61.5,

FITC-mouse IgG1, $\lambda$ isotype (G0114F7,

BD, 558689)

BioLegend, 401913)

PE-anti-mouse FoxP3 (NRRF-30,

PE-mouse IgG, 2a, $\mathrm{k}$ isotype

eBioscience, 12-4771-80)

(MOPC-173, BioLegend, 400211)

FITC, fluorescein isothiocyanate; APC, allophycocyanin; PE, phycoerythrin.

44 and $70 \%$ layers was pipetted into another round-bottom centrifuge tube, diluted with $10 \mathrm{ml}$ of PBS, and centrifuged at $300 \mathrm{x}$ g for $5 \mathrm{~min}$ to remove the Percoll or small particulates. The collected pellet was then used for flow cytometric analysis.

Isolation of nä̈ve $C D 8^{+} T$ cells from splenocytes. Splenocytes were obtained from the spleens of no cancer mice. Naïve $\mathrm{CD} 8^{+}$ $\mathrm{T}$ cells from splenocytes were isolated using a magnetic cell sorting kit (Naïve CD8 $\mathrm{a}^{+} \mathrm{T}$ Cell Isolation Kit, mouse, MACS $\mathrm{KK}$; Miltenyi Biotec) according to the manufacturer's instructions.

Flow cytometry. Samples $\left(2 \times 10^{6}\right.$ cells $\left./ \mathrm{ml}\right)$ were suspended in $500 \mu \mathrm{l}$ of PBS/1\% BSA and analyzed by flow cytometry (FACSCalibur flow cytometer; Becton-Dickinson, Mountain
View, CA, USA). Matched isotype antibodies were used as controls. T cells and neutrophils were stained with the antibodies listed in Table I.

ELISA. Cytokine levels [interleukin (IL)-6 and IFN- $\gamma$ ] were measured in ascites or culture media with a specific ELISA kit (DuoSet ELISA; R\&D Systems, Minneapolis, MN, USA) according to the manufacturer's instructions.

Coculture of neutrophils and naïve $C D 8^{+} T$ cells. T cell proliferation induced by plate-bound anti-mouse CD3e (1 $\mu \mathrm{g} / \mathrm{ml}$; BioLegend, San Diego, CA, USA; clone: 145-2C11) was assessed using standard carboxyfluorescein diacetate succinimidyl ester (CFSE; Cayman Chemical, Ann Arbor, MI, USA) dilution methods. Purified naïve $\mathrm{CD}^{+} \mathrm{T}$ cells $\left(2.0 \times 10^{6}\right.$ cells $\left./ \mathrm{ml}\right)$ were labeled with CFSE and cocultured 
A
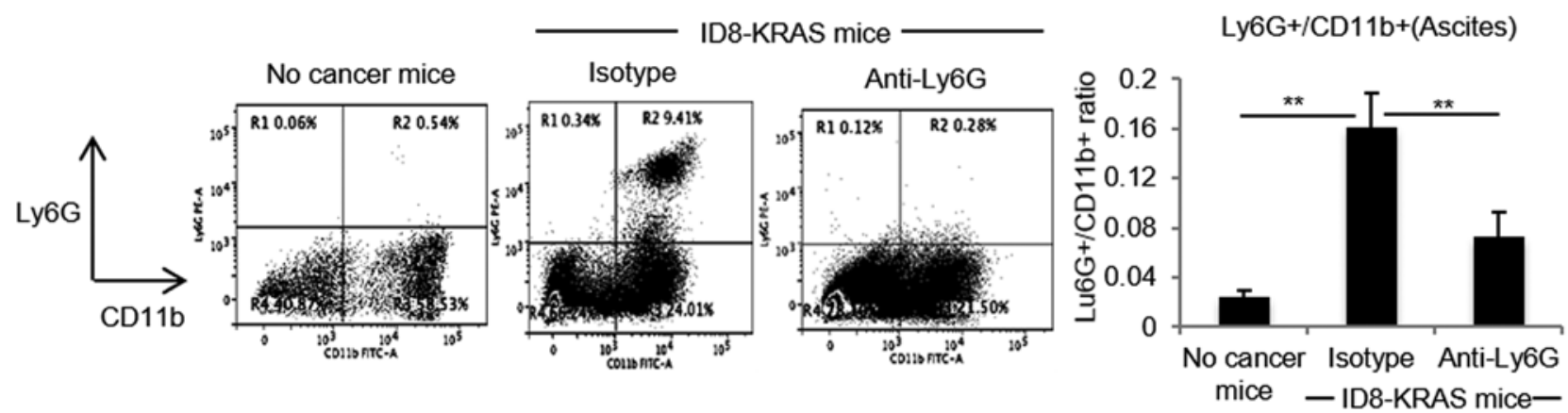

B
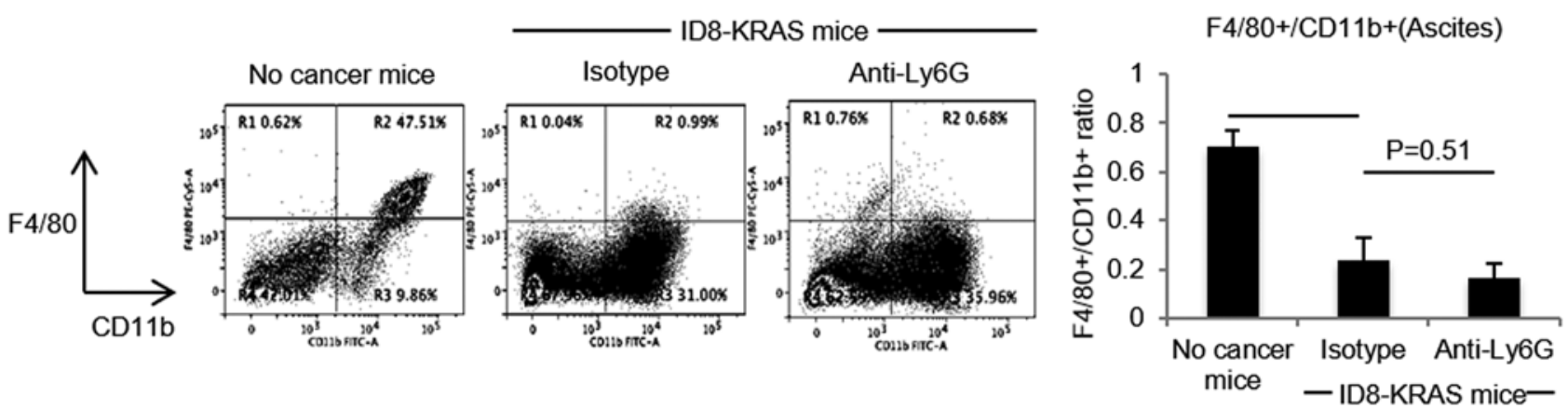

C ID8-KRAS mice
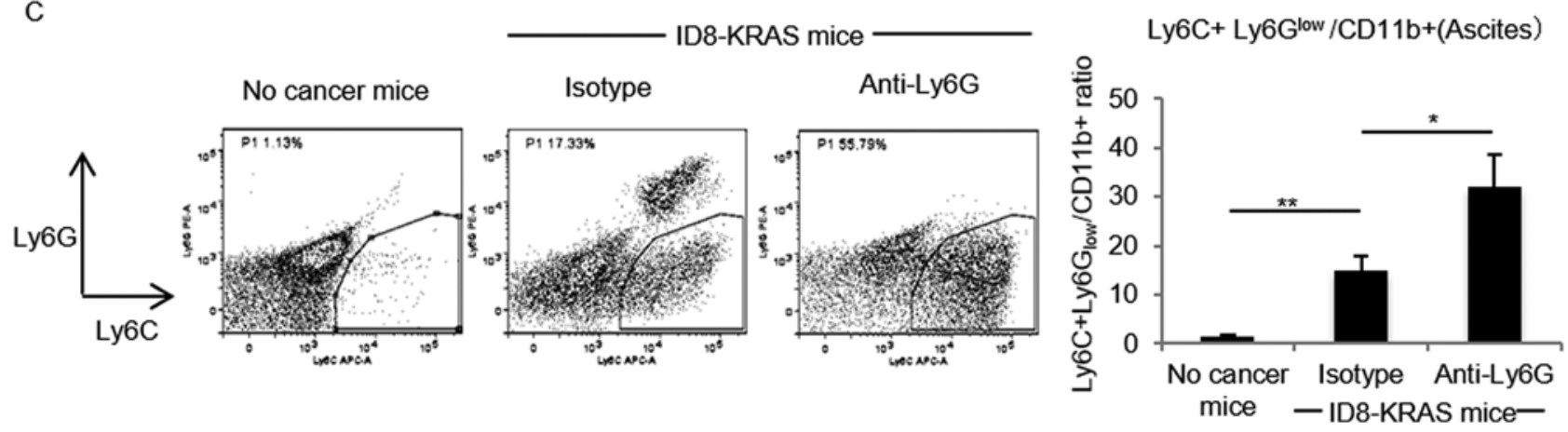

Figure 1. Effects of neutrophil depletion on peritoneal myelocytes. Murine ID8-KRAS cells $\left(2 \times 10^{6}\right)$ were intraperitoneally injected into 17 mice (isotype, $\mathrm{n}=8$ and anti-Ly6G, n=9). The mice were intraperitoneally injected with $250 \mu \mathrm{g}$ of anti-Ly6G mAb or matched isotype in $0.5 \mathrm{ml}$ of PBS every 3 days from day 7 after the inoculation of ID8-KRAS cells. Peritoneal myelocytes were obtained from ascites of no cancer mice ( $\mathrm{n}=6$ ) and ID8-KRAS mice treated with anti-Ly6G or isotype $\mathrm{mAb}$ after washing with $3 \mathrm{ml}$ of PBS. The depletion status was confirmed by assessing the proportion of $(\mathrm{A}) \mathrm{Ly} 6 \mathrm{G}^{+} / \mathrm{CD} 11 \mathrm{~b}^{+}$cells, (B) F4/80/CD11b ${ }^{+}$cells, and (C) Ly6C ${ }^{+}$Ly6Glow cells after gating for CD11b by flow cytometry. Peritoneal myelocytes were stained with the following antibodies: FITC-anti-mouse CD11b, PE-anti-mouse Ly6G, APC-anti-mouse Ly6C and PE-Cyanine5-anti-mouse F4/80. Error bars represent the means \pm SEM. Statistical analysis was performed using the Student's t-test. The P-value was adjusted with the Holm's method $\left({ }^{*} \mathrm{P}<0.05,{ }^{* *} \mathrm{P}<0.01\right)$.

with neutrophils $\left(2.0 \times 10^{6}\right.$ cells $\left./ \mathrm{ml}\right)$ obtained from the blood or ascites of each mouse (no-cancer control, ID8 mice, or ID8-KRAS mice) in CD3-coated plates for 3 days in complete cell culture medium. The complete cell culture medium was composed of RPMI-1640 medium (Wako) supplemented with $10 \% \mathrm{FBS}, 100 \mathrm{U} / \mathrm{ml}$ penicillin, $0.1 \mathrm{mg} / \mathrm{ml}$ streptomycin and $0.25 \mathrm{~g} / \mathrm{ml}$ amphotericin B. To establish whether $\mathrm{T}$ cell proliferation was induced by intercellular communication, we assessed cocultures using chambers. Five hundred microliters of neutrophils obtained from the ascites of ID8-KRAS mice were added to the upper compartments of the chambers at a concentration of $2.0 \times 10^{6}$ cells $/ \mathrm{ml}$. Five hundred microliters of purified naïve $\mathrm{CD}^{+} \mathrm{T}$ cells were seeded onto the bottom chamber at a concentration of $2.0 \times 10^{6}$ cells $/ \mathrm{ml}$. Following a 3-day incubation, cells on the upper chamber were completely removed. The CFSE signal was analyzed by flow cytometry.

Statistical analysis. Data are presented as the means \pm SEM. The log-rank test was used to detect differences in animal survival (Kaplan-Meier survival curves). All other comparisons were performed with the two-tailed Student's t-test. For performing multiple comparisons, all the P-values were adjusted by the Holm's method using the Microsoft Office Excel 2015 (BellCurve, Tokyo, Japan). Other statistical analyses were conducted using JMP11 (SAS Institute Japan, Tokyo, Japan). Other statistical analyses were conducted using JMP11 (SAS Institute Japan, Tokyo, Japan). A value of $\mathrm{P}<0.05$ was considered to indicate a statistically significant difference. 
A

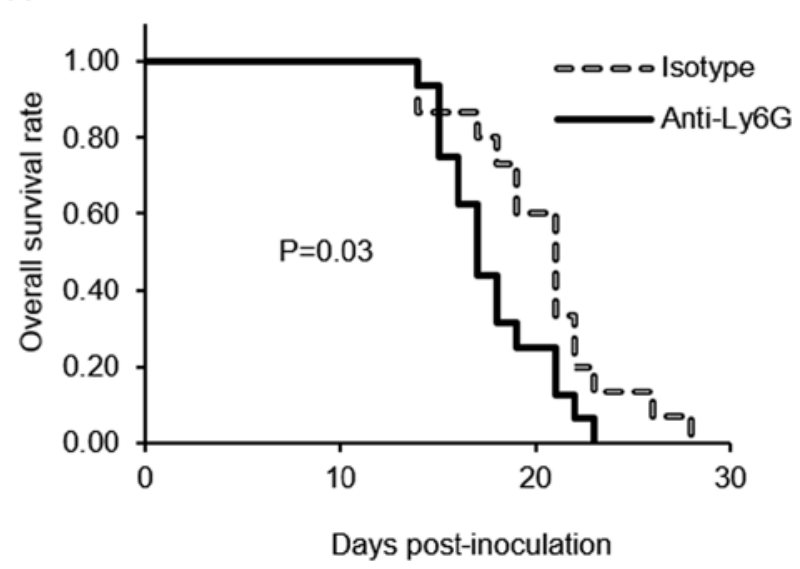

B

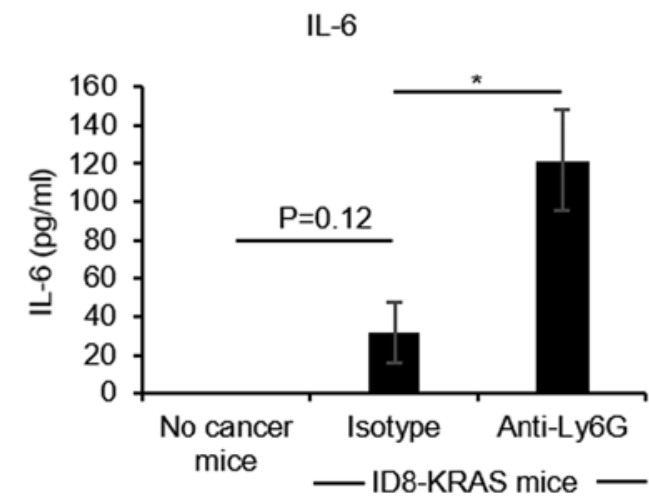

Figure 2. Effects of neutrophil depletion on cancer progression. (A) Murine ID8-KRAS cells $\left(2 \times 10^{6}\right)$ were intraperitoneally injected into 31 mice (isotype, $\mathrm{n}=15$; and anti-Ly6G, $\mathrm{n}=16$ ). The mice were intraperitoneally injected with $250 \mu \mathrm{g}$ of anti-Ly6G mAb or matched isotype in $0.5 \mathrm{ml}$ of PBS every 3 days from day 7 after inoculation of ID8-KRAS cells. For the mice survival analysis, the end point was determined as 'body weight $(\mathrm{BW})=23 \mathrm{~g}$ ', and mice were sacrificed when their BW exceeded $23 \mathrm{~g}$ after inoculation. The log-rank test was used to detect differences (Kaplan-Meier survival curves). (B) ID8-KRAS-injected mice were treated with anti-Ly6G mAb $(n=9)$ or isotype control $\mathrm{mAb}(\mathrm{n}=8)$ from day 10 after the inoculation of ID8-KRAS cells, and the ascites were obtained on day 16 after washing with $3 \mathrm{ml}$ of PBS The ascites from no cancer mice were also obtained after washing with $3 \mathrm{ml}$ of PBS $(n=6)$. The interleukin (IL)- 6 concentration in ascites of the 3 groups (no cancer, ID8-KRAS treated with isotype mAb, and ID8-KRAS treated with anti-Ly6G mAb) was analyzed using specific ELISA kits. Error bars represent the means \pm SEM. Statistical analysis was performed using the Student's t-test. The P-value was adjusted using the Holm's method ( $\mathrm{P}<0.05)$.

Study approval. Animal studies were approved by the University of Tokyo Animal Committee. Our IACUC permitted this study and provided this study the approval numbers P-14-027 and P15-060.

\section{Results}

Neutrophil depletion modulates the peritoneal microenvironment. We previously reported that the neutrophil count is markedly increased in ID8-KRAS-induced ascites (8), and demonstrated that neutrophil recruitment into the peritoneal cavity begins at around 10 days after the intraperitoneal injection. Therefore, in this study, we focused in particularly on neutrophil functions in the late phase and began the depletion of neutrophils 10 days after the injection. To investigate the role of increased neutrophils in the peritoneal microenvironment, neutrophils were depleted with a specific antibody, anti-Ly6G $\mathrm{mAb}$, and its isotype antibody was used as the control. Profiles of intraperitoneal myelocytes were assessed by flow cytometry. We first confirmed that the isotype antibody had no effect on the myelocyte population in ascites (data not shown). When compared with the isotype antibody, the anti-Ly6G antibody successfully decreased the $\mathrm{Ly} 6 \mathrm{G}^{+} / \mathrm{CD} 1 \mathrm{~b}^{+}$neutrophil numbers $(\mathrm{P}<0.01$, Fig. 1A); however, no significant difference was observed in the number of $\mathrm{F} 4 / 80^{+} / \mathrm{CD} 1 \mathrm{~b}^{+}$macrophages between the isotype and neutrophil-depleted groups $(\mathrm{P}=0.51$, Fig. 1B). Focusing on the profiles of myeloid-derived suppressor cells (MDSCs), the amount of Ly6 $\mathrm{C}^{+} \mathrm{Ly} 6 \mathrm{G}^{\text {low }}$ CD11 ${ }^{+}$monocytic-MDSCs (M-MDSCs) was significantly increased between the isotype and neutrophil-depleted groups $(\mathrm{P}<0.05$, Fig. $1 \mathrm{C})$.

Neutrophil depletion accelerates cancer progression and aggravates inflammation. We then investigated the effects of neutrophils on cancer progression. We first confirmed that the isotype antibody had no effect on the accumulation of ascites $(\mathrm{P}=0.18$, data not shown). When compared with the isotype group, the neutrophil-depleted group exhibited a more rapid accumulation of ascites ( $\mathrm{P}=0.03$, Fig. $2 \mathrm{~A}$ ).

A higher level of IL-6 is a hallmark of ovarian cancer progression $(23,24)$. In addition, increases in IL-6 production have been observed in KRAS-induced ovarian cancer (8); therefore, in this study, we measured the IL- 6 concentration as a surrogate marker of cancer progression. Neutrophil depletion significantly increased the IL- 6 concentration in ascites compared with that in the isotype group ( $\mathrm{P}<0.05$, Fig. $2 \mathrm{~B})$.

Neutrophil depletion modulates the $T$ cell profile in ascites and spleen. We examined the effects of neutrophils on the $\mathrm{T}$ lymphocyte population. Differences in the $\mathrm{CD} 4 / \mathrm{CD} 3 \varepsilon$ ratio and $C D 8 / C D 3 \varepsilon$ ratio in the spleen and ascites were compared between the isotype and neutrophil-depleted groups. The CD4/CD3 $\varepsilon$ ratio in the KRAS-induced ascites was significantly increased by neutrophil depletion $(\mathrm{P}<0.05$, Fig. $3 \mathrm{~A})$. On the contrary, the CD8/CD3e ratio in the KRAS-induced ascites and spleen was reduced by neutrophil depletion $(\mathrm{P}<0.05$, Fig. 3B).

Neutrophil depletion increases the number of regulatory $T$ cells in ascites. Previous studies have demonstrated that M-MDSCs induce regulatory $\mathrm{T}$ cell (Treg) differentiation (25-27). The data of this study indicated that an increased number of Ly6C ${ }^{+}$Ly6Glow/CD11b ${ }^{+}$M-MDSCs was accompanied by an increased number of $\mathrm{CD} 4^{+} \mathrm{T}$ cells. Therefore, we hypothesized that in the neutrophil-depleted group, the number of Tregs would be increased. The number of Tregs was assessed by FoxP3-CD25-CD4 flow cytometry. The number of Fox $3^{+} \mathrm{CD} 25^{+} / \mathrm{CD} 4^{+}$Tregs tended to be increased in the KRAS-induced ascites, and their number was markedly increased by neutrophil depletion $(\mathrm{P}<0.05$, Fig. $4 \mathrm{~A})$; however, their number did not significantly differ in the spleen (Fig. 4B).

Neutrophils from ID8-KRAS ascites stimulated CD8 T cell activity. The results of the in vivo assessment suggested that neutrophils also modulate $\mathrm{CD} 8^{+} \mathrm{T}$ cell activity. Therefore, 
A

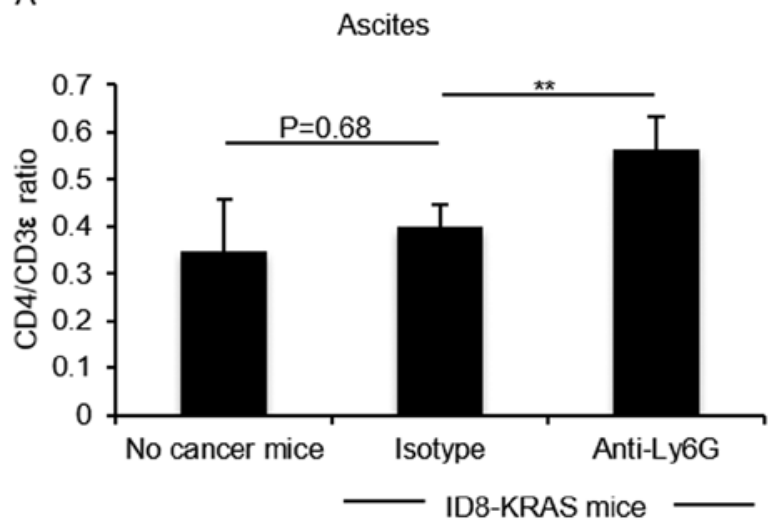

B

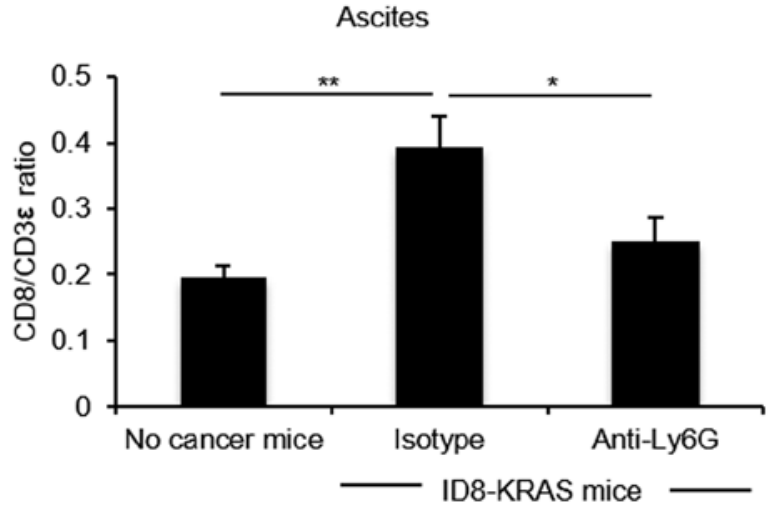

Spleen

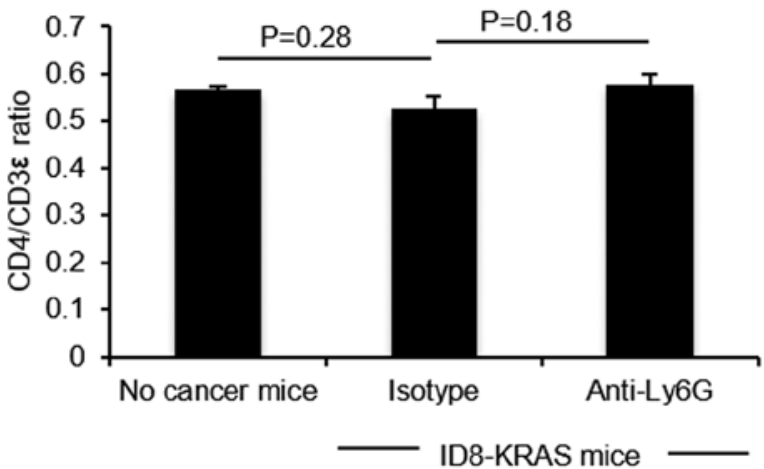

Spleen

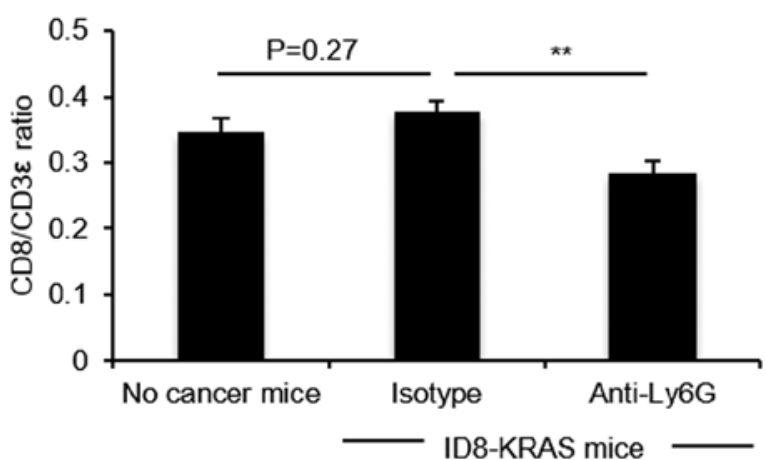

Figure 3. Effects of neutrophil depletion on the T cell subset. ID8-KRAS-injected mice were treated with anti-Ly6G mAb $(n=9)$ or isotype control $m A b(n=8)$ from day 10 after the inoculation of ID8-KRAS cells and sacrificed on day 16. No cancer mice were used as controls ( $\mathrm{n}=6$ ). Ascites and spleen were obtained from the no-cancer mice and ID8-KRAS mice treated with anti-Ly6G or isotype mAb after washing with $3 \mathrm{ml}$ of PBS. T cells were collected by Percoll density gradient $(44 \% / 70 \%)$. T cells were stained with the following antibodies: PE-Cy5-anti-mouse CD3e, FITC-anti-mouse CD8a, and APC-anti-mouse CD4. The (A) CD4/CD3 $\varepsilon$ ratio of ascites and spleen and (B) CD8/CD3 $\varepsilon$ ratio of ascites and spleen were analyzed by flow cytometry. Error bars represent the means \pm SEM. Statistical analysis was performed using the Student's t-test. The P-value was adjusted using the Holm's method $\left({ }^{*} \mathrm{P}<0.05,{ }^{* *} \mathrm{P}<0.01\right)$.

A

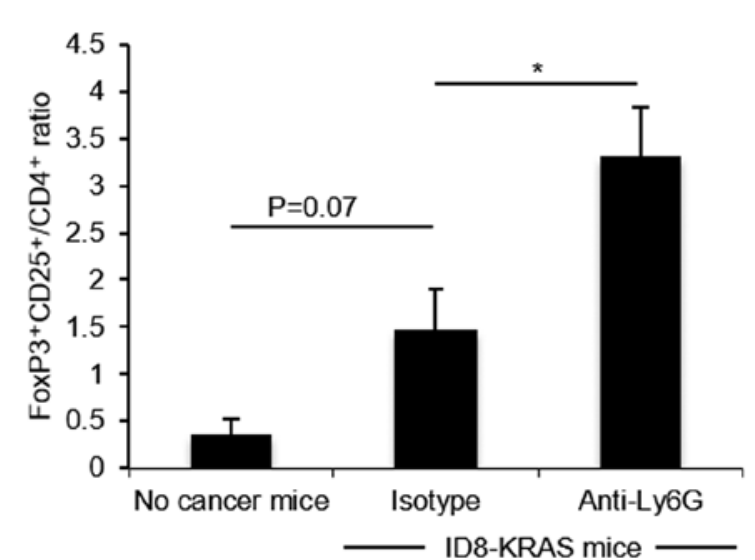

B

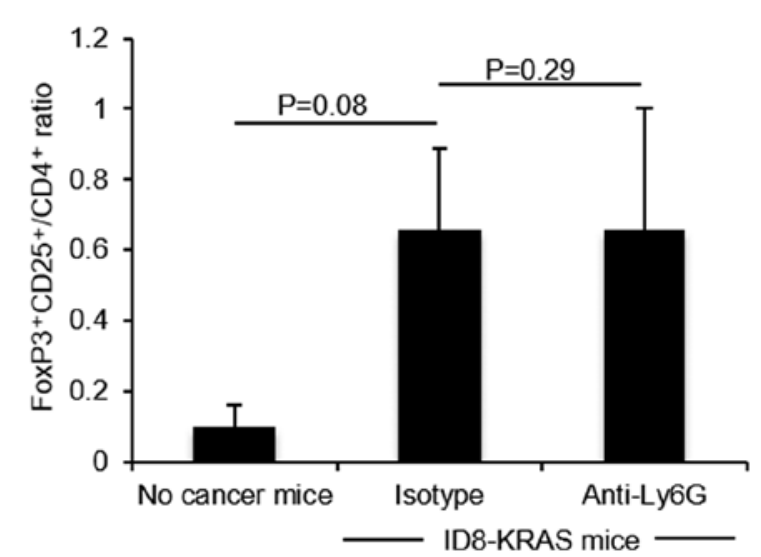

Figure 4. Effects of neutrophil depletion on Tregs. ID8-KRAS-injected mice were treated with anti-Ly6G mAb $(\mathrm{n}=9)$ or isotype control $\mathrm{mAb}(\mathrm{n}=8)$ from day 10 after the inoculation of ID8-KRAS cells and sacrificed on day 16. No cancer mice were used as controls $(\mathrm{n}=6)$. Ascites and spleen were obtained from the no cancer mice and ID8-KRAS mice treated with anti-Ly6G or isotype mAb after washing with $3 \mathrm{ml}$ of PBS. T cells were collected by Percoll density gradient $(44 \% / 70 \%)$. T cells were stained with the following antibodies: FITC-anti-mouse CD25, APC-anti-mouse CD4, and PE-anti-mouse FoxP3. The FoxP $3{ }^{+} \mathrm{CD} 25^{+} / \mathrm{CD}^{+}$ratio of (A) ascites and (B) spleen was analyzed by flow cytometry. Error bars represent the means \pm SEM. Statistical analysis was performed using the Student's t-test. The P-value was adjusted using the Holm's method ("P<0.05).

we assessed the effects of neutrophils on $\mathrm{CD}^{+} \mathrm{T}$ cell activity in vitro. Naïve $\mathrm{CD} 8^{+} \mathrm{T}$ cells were cultured with anti-CD3 antibody alone or with peripheral blood neutrophils (PBNs) or peritoneal neutrophils (PENs) from each mouse (no cancer mice and ID8-KRAS mice). The proliferation of naïve $\mathrm{CD} 8^{+}$ $\mathrm{T}$ cells was assessed using CFSE staining. $\mathrm{CD}^{+} \mathrm{T}$ cell 
A

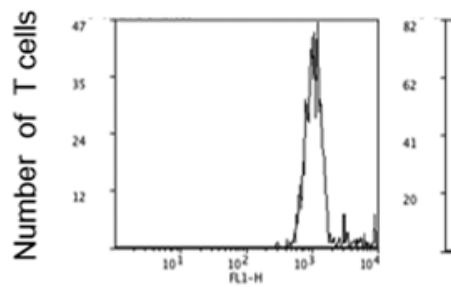

CFSE

Anti-CD3

$(-)$

Neutrophils

$(-)$

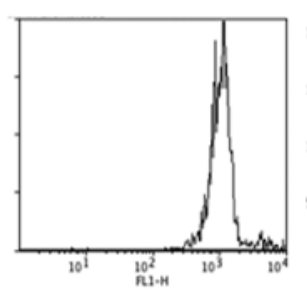

$(+)$

$(-)$

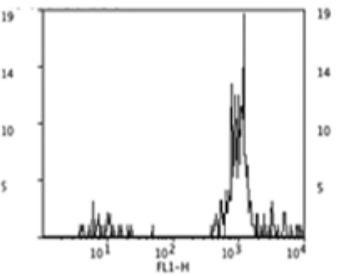

$(+)$

PBN

No cancer mice

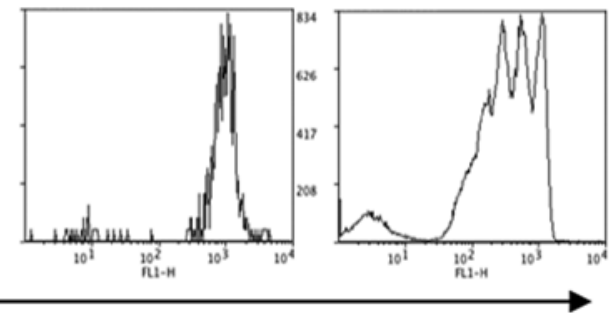

$(+)$

$(+)$

B

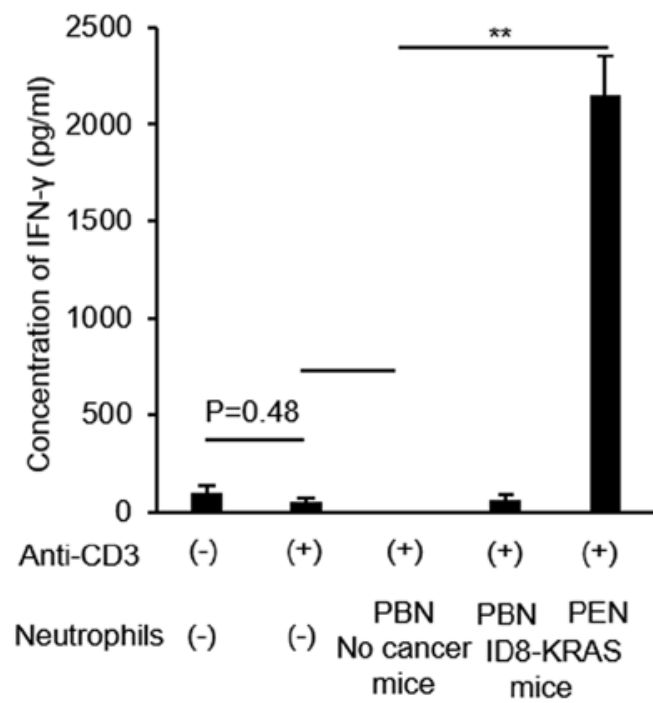

C

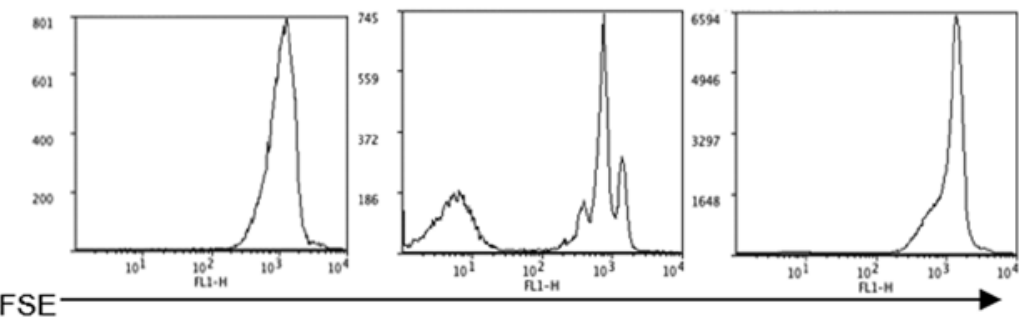

Anti-CD3

$(+)$

$(+)$

$(+)$

Neutrophils
PEN ID8-KRAS mice

Figure 5. In vitro effects of neutrophils on $\mathrm{CD}^{+} \mathrm{T}$ cell activation. CFSE-labeled naïve $\mathrm{CD} 8^{+} \mathrm{T}$ cells were isolated from the spleen of no cancer mice ( $\mathrm{n}=8$ ). Naïve $\mathrm{CD}^{+} \mathrm{T}$ cells $\left(2.0 \times 10^{6}\right.$ cells $\left./ \mathrm{ml}\right)$ were cocultured with neutrophils $\left(2.0 \times 10^{6}\right.$ cells $\left./ \mathrm{ml}\right)$ from each group under stimulation of plate-bound anti-CD3 antibody for 3 days. Neutrophils were obtained from PBNs of no cancer mice or PBNs and PENs of ID8-KRAS mice (n=8). PBN and PEN indicate peripheral blood neutrophil and peritoneal neutrophils, respectively. (A) The CFSE signal was analyzed by flow cytometry. The data provided are representative results of 3 independent experiments. (B) The concentration of IFN- $\gamma$ in the supernatant of each culture medium was analyzed by specific ELISA. The data provided are representative results of 3 independent experiments. Error bars represent the means \pm SEM. Statistical analysis was performed using the Student's t-test. The P-value was adjusted using the Holm's method $\left({ }^{*} \mathrm{P}<0.05,{ }^{* *} \mathrm{P}<0.01\right)$. (C) To assess the effects of cell-to-cell interactions between $\mathrm{T}$ cells and neutrophils, PENs of ID8-KRAS mice were added to the upper compartments of the chambers at a concentration of $2.0 \times 10^{6}$ cells $/ \mathrm{ml}$. Naïve CD8 ${ }^{+} \mathrm{T}$ cells were added to the bottom chamber at a concentration of $2.0 \times 10^{6}$ cells $/ \mathrm{ml}$ and cocultured for 3 days in CD3-coated plates. The CFSE signal was analyzed by flow cytometry. The data provided are representative results of 3 independent experiments.

proliferation markedly increased in coculture with PENs from ID8-KRAS mice (Fig. 5A). IFN- $\gamma$ production by $\mathrm{CD}^{+}$ $\mathrm{T}$ cells was also assessed in each group using specific ELISA kits. When compared with the PBNs from no cancer mice or ID8-KRAS mice, coculture with PENs from ID8-KRAS mice markedly increased IFN- $\gamma$ production by naïve $\mathrm{CD} 8^{+}$ $\mathrm{T}$ cells (Fig. 5B). The T cell stimulatory effects of PENs from ID8-KRAS mice were reversed when PENs from ID8-KRAS mice were added to the coculture chamber, suggesting that cell-to-cell contact was indispensable for the $\mathrm{T}$ cell stimulatory effects of KRAS-related neutrophils (Fig. 5C).

T cell costimulatory molecules are expressed at high levels in neutrophils from ID8-KRAS ascites. To elucidate the mechanisms through which PENs from ID8-KRAS mice strongly promote IFN- $\gamma$ production and the proliferation of $\mathrm{CD}^{+} \mathrm{T}$ cells, $\mathrm{T}$ cell costimulatory molecules CD80, CD86, OX40 ligand (OX40L) and 4-1BB ligand (4-1BBL) on the surface of neutrophils from no cancer mice, ID8 mice and ID8-KRAS mice were assessed by flow cytometry. Almost no difference in CD80 and CD86 expression in the PBNs and PENs was observed among these 3 groups (Fig. 6A and B). Furthermore, no significant differences in CD80 and CD86 expression between the PBNs and PENs was noted in each mouse group (Fig. 6A and B). The ID8-KRAS mice expressed higher levels of 4-1BBL in both the PBNs and PENs (Fig. 6C) (PBNs: no cancer vs. ID8-KRAS, $\mathrm{P}<0.01$; ID8 vs. ID8-KRAS, $\mathrm{P}=0.05$; PENs: ID8 vs. ID8-KRAS, $\mathrm{P}<0.05)$. No significant differences were observed between the PBNs and PENs in each mouse group (ID8 mice, $\mathrm{P}=0.20$; ID8-KRAS mice, 

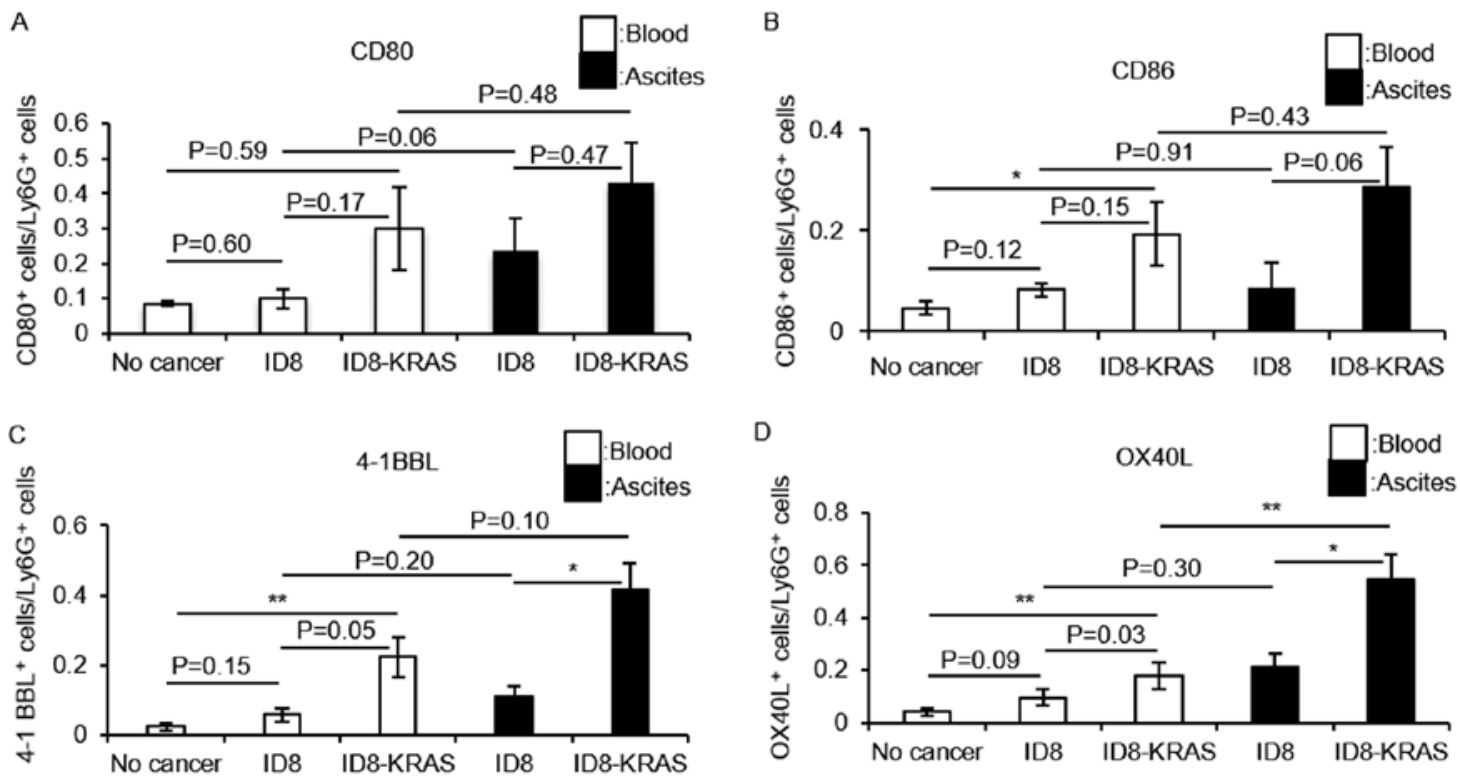

Figure 6. Expression of T cell costimulatory molecules on neutrophils. Murine ID8 cells $\left(2 \times 10^{6}\right)$ and ID8-KRAS cells $\left(2 \times 10^{6}\right)$ were injected into mice, and neutrophils were obtained from ascites or blood when the body weight exceeded $23 \mathrm{~g}$. Neutrophils from no cancer mice were used as a control. (A-D) The expression of costimulatory molecules on the gated $\mathrm{Ly} \mathrm{g}^{+}$neutrophils from ascites or blood was analyzed by flow cytometry. The number of mice used in each experiment was as follows: (A) CD80: no cancer, $n=8$; ID8, n=5; ID8-KRAS, $n=7$; (B) CD86: no cancer, n=6; ID8, n=6; ID8-KRAS, n=5; (C) 4-1BBL: no cancer, $n=11$; ID8, n=5; ID8-KRAS, n=7; (D) OX40L: no cancer, $n=10$; ID8, n=5; ID8-KRAS, n=8. Error bars represent the means \pm SEM. Statistical analysis was performed using the Student's t-test. The P-value was adjusted using the Holm's method $\left({ }^{*} \mathrm{P}<0.05,{ }^{* *} \mathrm{P}<0.01\right)$. PBNs and PENs indicate peripheral blood neutrophils and peritoneal neutrophils, respectively.

A

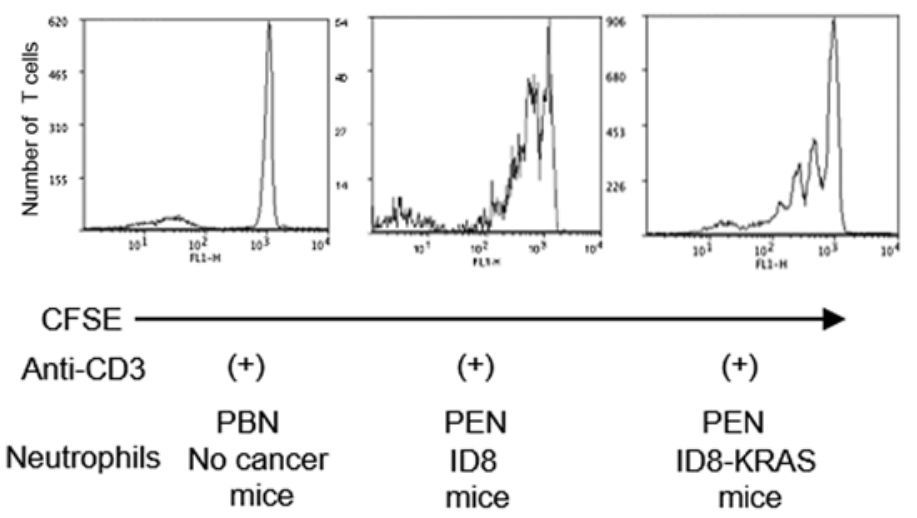

B

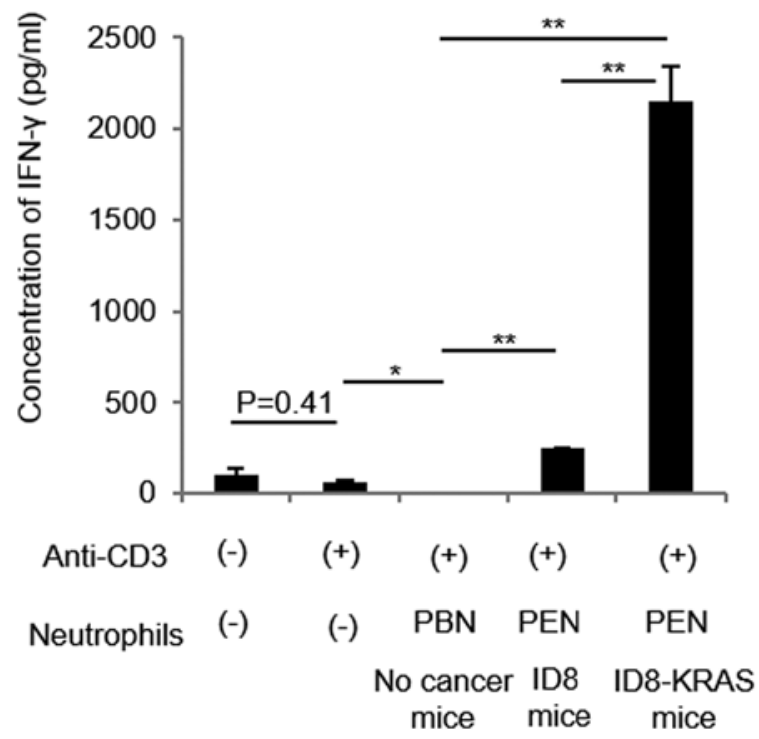

Figure 7. In vitro effects of neutrophils on activation of $\mathrm{CD} 8^{+} \mathrm{T}$ cells from ID8 mice. CFSE-labeled naïve $\mathrm{CD} 8^{+} \mathrm{T}$ cells were isolated from the spleen of no cancer mice $(\mathrm{n}=8)$. Naïve $\mathrm{CD} 8^{+} \mathrm{T}$ cells $\left(2.0 \times 10^{6}\right.$ cells $\left./ \mathrm{ml}\right)$ were cocultured with neutrophils $\left(2.0 \times 10^{6} \mathrm{cell} / \mathrm{s} / \mathrm{ml}\right)$ from each group under stimulation of plate-bound anti-CD3 antibody for 3 days. Neutrophils were obtained from PBNs of no cancer mice or PENs of ID8 mice $(\mathrm{n}=8)$ and ID8-KRAS mice (n=8). PBNs and PENs indicate peripheral blood neutrophils and peritoneal neutrophils, respectively. (A) The CFSE signal was analyzed by flow cytometry. The data provided are representative results of 3 independent experiments. (B) The concentration of IFN- $\gamma$ in the supernatant of each culture medium was analyzed by specific ELISA. The data provided are representative results of 3 independent experiments. Error bars represent the means \pm SEM. Statistical analysis was performed using the Student's t-test. The P-value was adjusted using the Holm's method $\left({ }^{*} \mathrm{P}<0.05,{ }^{* *} \mathrm{P}<0.01\right)$.

$\mathrm{P}=0.10$, respectively). Marked differences were observed in the expression levels of OX40L. In both the PBNs and PENs, the OX40L expression levels were significantly higher in the ID8-KRAS mice than in the no cancer mice and ID8 mice (Fig. 6D) (PBNs: no cancer vs. ID8-KRAS, P<0.01; ID8 vs.
ID8-KRAS, $\mathrm{P}=0.03$; PENs: ID8 vs. ID8-KRAS, $\mathrm{P}<0.05$ ). When the PBNs and PENs from each mouse were compared, the PENs from the ID8-KRAS mice exhibited a higher expression of OX40L than the PBNs (Fig. 6D) (ID8 mice, $\mathrm{P}=0.30$; ID8-KRAS mice, $\mathrm{P}<0.01$, respectively). 


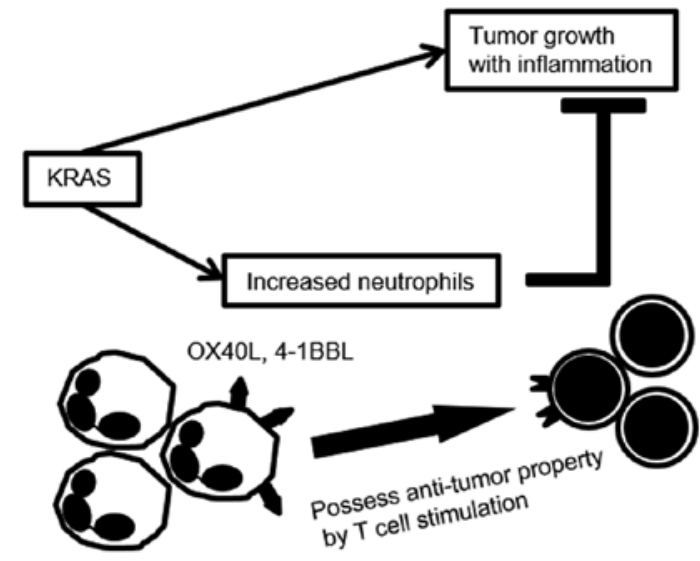

Figure 8. Schematic diagram illustrating intraperitoneal neutrophils activated by KRAS-induced ovarian cancer. The increased number of neutrophils in KRAS-induced ascites possessed antitumor properties by modulating the tumor microenvironment (TME).

$C D 8^{+} T$ cell stimulatory function on neutrophils is much stronger in ID8-KRAS mice than in ID8 mice. ID8-KRASassociated neutrophils possessed $\mathrm{T}$ cell stimulatory function with higher expression of OX40L and 4-1BBL. We next evaluated whether $\mathrm{T}$ cell stimulatory properties of neutrophils were present in any cancer-related microenvironment. Therefore, we compared $\mathrm{T}$ cell stimulatory effects between neutrophils from ID8-induced ascites and those from ID8-KRAS-induced ascites. PENs from ID8-induced ascites slightly activated $\mathrm{CD}^{+} \mathrm{T}$ cells by inducing IFN- $\gamma$ production, as well as stimulating $\mathrm{CD}^{+} \mathrm{T}$ cell proliferation, which was much weaker than that promoted by PENs from ID8-KRAS-induced ascites (Fig. 7).

A comparison of $\mathrm{T}$ cell costimulatory molecules between ID8 and ID8-KRAS revealed that the OX40L and 4-1BBL expression levels in PENs were significantly lower in ID8 mice than in ID8-KRAS mice (Fig. 8).

\section{Discussion}

In the current study, we found that neutrophil depletion in the ID8-KRAS model accelerated tumor formation and aggravated IL-6-associated inflammation. Neutrophil depletion increased the number of $\mathrm{Ly} 6 \mathrm{C}^{+} \mathrm{Ly} 6 \mathrm{G}^{\mathrm{low}} / \mathrm{CD} 11 \mathrm{~b}^{+} \mathrm{M}-\mathrm{MDSCs}$ accompanied with an increased number of Tregs in ascites. Furthermore, the neutrophil depletion decreased the $\mathrm{CD} 8^{+}$ T cell population. PENs from ID8-KRAS mice exhibited strong potential to enhance $\mathrm{T}$ cell proliferation with a higher expression of $\mathrm{T}$ cell costimulatory molecules compared with the PENs from ID8 mice.

A number of studies have reported that an elevated neutrophil count or an increased $\mathrm{N} / \mathrm{L}$ ratio in blood is a poor prognostic marker in several cancer types (28-31). The results of our previous study (8) also support the above finding that an increased neutrophil count, which may induce an increased N/L ratio, was observed in ID8-KRAS-induced rapid cancer progression. However, in our model, neutrophil depletion appeared to accelerate tumor formation. These findings suggest that the increase in TANs in our model had antitumor effects.
The results of this study revealed that neutrophil depletion increased the number of $\mathrm{CD}^{+} \mathrm{T}$ cells in ascites, particularly the Tregs fraction. Furthermore, we revealed that neutrophil depletion increased the M-MDSC population. MDSCs are subdivided into two major groups: Polymorphonuclear MDSCs (PMN-MDSCs) and M-MDSCs. PMN-MDSCs have a morphology similar to that of granulocytes, and M-MDSCs are morphologically similar to monocytes. In mice, PMN-MDSCs have a phenotype of CD11 ${ }^{+} \mathrm{Ly} 6 \mathrm{C}^{-} \mathrm{Ly} 6 \mathrm{G}^{\text {high }}$, whereas M-MDSCs have a phenotype of CD11 ${ }^{+} \mathrm{Ly} 6 \mathrm{G}^{-} \mathrm{Ly} 6 \mathrm{C}^{\text {high }}$ $(32,33)$. In our model, the MDSCs increased by neutrophil depletion were classified as M-MDSCs with the phenotype of CD11b ${ }^{+}$Ly6G-Ly6 $\mathrm{C}^{\text {high }}$. There is substantial variability in the M-MDSC proportion depending on the type of cancer. Patients with melanoma and prostate cancer have a substantially higher proportion of M-MDSCs in the peripheral blood than PMN-MDSCs (34). In ovarian cancer, M-MDSCs have been reported to be present in both the periphery and ascites. Ascite-derived IL-6 and IL-10 and their downstream signal transducer and activator of transcription 3 (STAT3) signal are critically responsible for the accumulation and suppressive activity of M-MDSCs (35). M-MDSCs potently suppress nonspecific T cell responses, and on a per-cell basis, M-MDSCs have a high suppressive activity with a higher production of nitric oxide (NO), Arg1, TGF- $\beta$ and immunosuppressive cytokines (36-40). Furthermore, it has been previously demonstrated that TGF- $\beta$ induced Foxp3 gene expression in $\mathrm{T}$ cell receptor-challenged $\mathrm{CD} 4{ }^{+} \mathrm{CD} 25$ - peripheral naïve $\mathrm{T}$ cells, which were then transformed toward a Treg phenotype with potent immunosuppressive potential (41). In this model, M-MDSCs may contribute to cancer progression by inducing Treg differentiation and suppressing CD8 T cell activity.

The results of this study revealed that neutrophil depletion decreased the $\mathrm{CD} 8^{+} \mathrm{T}$ cell population in KRAS-induced ascites, suggesting that neutrophils promote $\mathrm{CD} 8^{+} \mathrm{T}$ cell proliferation or survival in the KRAS-induced environment. The finding that TANs in KRAS-induced ascites had a strong potential for promoting the proliferation of naïve $\mathrm{CD} 8^{+}$ $\mathrm{T}$ cells in vitro supports the results obtained in these in vivo assessments. In lung cancer, $\mathrm{T}$ cell costimulatory molecules are responsible for T cell activation by TANs (18). We also confirmed that TANs in KRAS-induced ascites expressed OX40L and 4-1BBL at higher levels than neutrophils from blood or TANs in ID8-induced ascites. The T cell-stimulatory effects of TANs from KRAS-induced ascites were reversed by chamber separation, suggesting that cell-to-cell interactions are indispensable for $\mathrm{T}$ cell activation. $\mathrm{T}$ cell costimulatory molecules on neutrophils may be responsible for the involvement of TANs in KRAS-induced ascites in promoting $\mathrm{T}$ cell proliferation.

Although the function of neutrophils in promoting $\mathrm{T}$ cell activation has already been reported (39), the types of tumors that induce neutrophils with antitumor properties have not yet been identified. In this study, PENs from ID8-KRAS mice possessed markedly stronger potential for $\mathrm{T}$ cell activation than PENs of ID8 mice. A difference was also observed between the OX40L and 4-1BBL expression levels on the neutrophil surfaces. Our results suggest that the KRASinduced environment generated neutrophils with portent antitumor properties. To the best of our knowledge, no study 
to date has demonstrated an association between oncogenes and the properties of neutrophils. The cancer-specific modulation of neutrophils has not yet been reported; however, the antitumor or protumor function of neutrophils may be related to the activated oncogenes and their specific TME. Furthermore, given that KRAS-related neutrophils possessed antitumor properties with increased expression of OX40L and 4-1BBL, OX40L- or 4-1BBL-based immunotherapy may be a therapeutic strategy for KRAS mutated cancer.

In the current study, we used anti-Ly6G mAb to deplete neutrophils. It is possible that $\mathrm{CD} 11 \mathrm{~b}^{+} \mathrm{Ly} 6 \mathrm{C}^{-} \mathrm{Ly} 6 \mathrm{G}^{\mathrm{high}}$ PMN-MDSCs were also depleted in our model as it is difficult to distinguish neutrophils from PMN-MDSCs. However, in our model, the depletion of Ly6Ghigh populations resulted in an enhanced cancer formation accompanied by the immunosuppressive microenvironment. Considering that MDSCs have an immunosuppressive function, it appeared that, in our model, a decreased number of neutrophils with immunostimulatory effects potently affected the TME compared with a decreased number of PMN-MDSCs with immunosuppressive effects. In addition, we only used a mouse ovarian cancer model to elucidate the association between the oncogene KRAS and the properties of neutrophils. Further studies utilizing clinical samples are warranted for the confirmation of the association identified in this study.

We herein propose that the increased number of neutrophils in KRAS-induced ascites possessed antitumor properties by modulating the TME, and that this effect was more potent in KRAS-associated neutrophils. Knowledge regarding these characteristics of neutrophil modification may provide a better understanding of the cancer-induced microenvironment.

\section{Acknowledgements}

The authors would like to thank Ms. Chiho Kohno (Division of Virology, National Cancer Center Research Institute) for the construction of the ID8-KRAS cells.

\section{Funding}

This study was supported by Japan Society for the Promotion of Science KAKENHI Grant number 16K11131 and 15H06172.

\section{Availability of data and materials}

The datasets used and/or analyzed during the current study are available from the corresponding author on reasonable request.

\section{Authors' contributions}

MY, AT, KKa, KK, TN and KO were involved in the conception and design of the study. MY, AT, KKa, KK, MM, OWH and TK were involved in the development of methodology. TK and $\mathrm{OWH}$ were involved in the establishment of cell lines and technical support. MY, AT, KKa and KA were involved in the acquisition of data. MY, AT, KKa, JO, AK, HN, MS, AF, TI, KT, MM, TN, TA, KKo, OWH, KO, TK, YO and TF were involved in the analysis and interpretation of data. MY, AT, $\mathrm{KKa}$ and $\mathrm{KA}$ were involved in the writing, reviewing, and/or revision of the manuscript. MY, AT, KKa, JO, KA and AK were involved in administrative, technical, or material support. MY, AT, KKa, MM, TN, TA, KKo, OWH, KO, TK, YO and TF supervised the study.

\section{Ethics approval and consent to participate}

The animal studies were approved by the University of Tokyo Animal Committee. Our IACUC permitted this study and gave this study the approval numbers P-14-027 and P15- 060.

\section{Patient consent for publication}

Not applicable.

\section{Competing interests}

The authors declare that they have no competing interests.

\section{References}

1. Trellakis S, Bruderek K, Dumitru CA, Gholaman H, Gu X, Bankfalvi A, Scherag A, Hütte J, Dominas N, Lehnerdt GF, et al: Polymorphonuclear granulocytes in human head and neck cancer: Enhanced inflammatory activity, modulation by cancer cells and expansion in advanced disease. Int J Cancer 129: 2183-2193, 2011.

2. Jensen HK, Donskov F, Marcussen N, Nordsmark M, Lundbeck F and von der Maase H: Presence of intratumoral neutrophils is an independent prognostic factor in localized renal cell carcinoma. J Clin Oncol 27: 4709-4717, 2009.

3. Jensen TO, Schmidt H, Møller HJ, Donskov F, Høyer M, Sjoegren P, Christensen IJ and Steiniche T: Intratumoral neutrophils and plasmacytoid dendritic cells indicate poor prognosis and are associated with pSTAT3 expression in AJCC stage I/II melanoma. Cancer 118: 2476-2485, 2012.

4. Templeton AJ, McNamara MG, Šeruga B, Vera-Badillo FE, Aneja P, Ocaña A, Leibowitz-Amit R, Sonpavde G, Knox JJ, Tran B, et al: Prognostic role of neutrophil-to-lymphocyte ratio in solid tumors: A systematic review and meta-analysis. J Natl Cancer Inst 106: dju124, 2014.

5. Taguchi S, Nakagawa T, Matsumoto A, Nagase Y, Kawai T, Tanaka Y, Yoshida K, Yamamoto S, Enomoto Y, Nose Y, et al: Pretreatment neutrophil-to-lymphocyte ratio as an independent predictor of survival in patients with metastatic urothelial carcinoma: A multi-institutional study. Int J Urol 22: 638-643, 2015.

6. Nakamura K, Nagasaka T, Nishida T, Haruma T, Ogawa C, Kusumoto T, Seki N and Hiramatsu Y: Neutrophil to lymphocyte ratio in the pre-treatment phase of final-line chemotherapy predicts the outcome of patients with recurrent ovarian cancer. Oncol Lett 11: 3975-3981, 2016.

7. Feng Z, Wen H, Bi R, Ju X, Chen X, Yang W and Wu X: Preoperative neutrophil-to-lymphocyte ratio as a predictive and prognostic factor for high-grade serous ovarian cancer. PLoS One 11: e0156101, 2016.

8. Yoshida M, Taguchi A, Kawana K, Adachi K, Kawata A, Ogishima J, Nakamura H, Fujimoto A, Sato M, Inoue T, et al: Modification of the tumor microenvironment in KRAS or c-MYC-induced ovarian cancer-associated peritonitis. PLoS One 11: $\mathrm{e} 0160330,2016$.

9. Chandler RL, Damrauer JS, Raab JR, Schisler JC, Wilkerson MD, Didion JP, Starmer J, Serber D, Yee D, Xiong J, et al: Coexistent ARID1A-PIK3CA mutations promote ovarian clear-cell tumorigenesis through pro-tumorigenic inflammatory cytokine signalling. Nat Commun 6: 6118, 2015.

10. Eser S, Schnieke A, Schneider G and Saur D: Oncogenic KRAS signalling in pancreatic cancer. Br J Cancer 111: 817-822, 2014.

11. Pylayeva-Gupta Y, Grabocka E and Bar-Sagi D: RAS oncogenes: Weaving a tumorigenic web. Nat Rev Cancer 11: 761-774, 2011.

12. Daniluk J, Liu Y, Deng D, Chu J, Huang H, Gaiser S, CruzMonserrate Z, Wang H, Ji B and Logsdon CD: An NF- $\kappa B$ pathway-mediated positive feedback loop amplifies Ras activity to pathological levels in mice. J Clin Invest 122: 1519-1528, 2012. 
13. Caruso RA, Bellocco R, Pagano M, Bertoli G, Rigoli L and Inferrera C: Prognostic value of intratumoral neutrophils in advanced gastric carcinoma in a high-risk area in northern Italy. Mod Pathol 15: 831-837, 2002.

14. Jablonska J, Leschner S, Westphal K, Lienenklaus S and Weiss S: Neutrophils responsive to endogenous IFN-beta regulate tumor angiogenesis and growth in a mouse tumor model. J Clin Invest 120: 1151-1164, 2010.

15. Fridlender ZG, Sun J, Kim S, Kapoor V, Cheng G, Ling L, Worthen GS and Albelda SM: Polarization of tumor-associated neutrophil phenotype by TGF-beta: 'N1' versus "N2" TAN. Cancer Cell 16: 183-194, 2009.

16. Li YW, Qiu SJ, Fan J, Zhou J, Gao Q, Xiao YS and Xu YF: Intratumoral neutrophils: A poor prognostic factor for hepatocellular carcinoma following resection. J Hepatol 54: 497-505, 2011

17. Houghton AM: The paradox of tumor-associated neutrophils: Fueling tumor growth with cytotoxic substances. Cell Cycle 9: $1732-1737,2010$

18. Eruslanov EB, Bhojnagarwala PS, Quatromoni JG, Stephen TL, Ranganathan A, Deshpande C, Akimova T, Vachani A, Litzky L, Hancock WW, et al: Tumor-associated neutrophils stimulate $\mathrm{T}$ cell responses in early-stage human lung cancer. J Clin Invest 124: 5466-5480, 2014

19. Sasaki R, Narisawa-Saito M, Yugawa T, Fujita M, Tashiro H, Katabuchi $\mathrm{H}$ and Kiyono T: Oncogenic transformation of human ovarian surface epithelial cells with defined cellular oncogenes. Carcinogenesis 30: 423-431, 2009.

20. Overmyer KA, Thonusin C, Qi NR, Burant CF and Evans CR: Impact of anesthesia and euthanasia on metabolomics of mammalian tissues: Studies in a C57BL/6J mouse model. PLoS One 10: e0117232, 2015.

21. Arnold L, Tyagi RK, Mejia P, Van Rooijen N, Pérignon JL and Druilhe P: Analysis of innate defences against Plasmodium falciparum in immunodeficient mice. Malar J 9: 197, 2010.

22. Xiao H, Heeringa P, Liu Z, Huugen D, Hu P, Maeda N, Falk RJ and Jennette JC: The role of neutrophils in the induction of glomerulonephritis by anti-myeloperoxidase antibodies. Am J Pathol 167: 39-45, 2005.

23. Tempfer C, Zeisler H, Sliutz G, Haeusler G, Hanzal E and Kainz C: Serum evaluation of interleukin 6 in ovarian cancer patients. Gynecol Oncol 66: 27-30, 1997.

24. Scambia G, Testa U, Benedetti Panici P, Foti E, Martucci R, Gadducci A, Perillo A, Facchini V, Peschle C and Mancuso S: Prognostic significance of interleukin 6 serum levels in patients with ovarian cancer. Br J Cancer 71: 354-356, 1995

25. Wang J, Yang L, Yu L, Wang YY, Chen R, Qian J, Hong ZP and Su XS: Surgery-induced monocytic myeloid-derived suppressor cells expand regulatory $\mathrm{T}$ cells in lung cancer. Oncotarget 8 : 17050-17058, 2017.

26. O'Connor MA, Vella JL and Green WR: Reciprocal relationship of $\mathrm{T}$ regulatory cells and monocytic myeloid-derived suppressor cells in LP-BM5 murine retrovirus-induced immunodeficiency. J Gen Virol 97: 509-522, 2016

27. Idorn M, Køllgaard T, Kongsted P, Sengel $\varnothing v$ L and Thor Straten P: Correlation between frequencies of blood monocytic myeloid-derived suppressor cells, regulatory $\mathrm{T}$ cells and negative prognostic markers in patients with castration-resistan metastatic prostate cancer. Cancer Immunol Immunother 63 $1177-1187,2014$

28. Rao HL, Chen JW, Li M, Xiao YB, Fu J, Zeng YX, Cai MY and Xie D: Increased intratumoral neutrophil in colorectal carcinomas correlates closely with malignant phenotype and predicts patients' adverse prognosis. PLoS One 7: e30806, 2012.
29. Yamanaka T, Matsumoto S, Teramukai S, Ishiwata R, Nagai Y and Fukushima M: The baseline ratio of neutrophils to lymphocytes is associated with patient prognosis in advanced gastric cancer. Oncology 73: 215-220, 2007

30. Nuhn P, Vaghasia AM, Goyal J, Zhou XC, Carducci MA, Eisenberger MA and Antonarakis ES: Association of pretreatment neutrophil-to-lymphocyte ratio (NLR) and overall survival (OS) in patients with metastatic castration-resistant prostate cancer (mCRPC) treated with first-line docetaxel. BJU Int 114 (6b): E11-E17, 2014.

31. Azab B, Bhatt VR, Phookan J, Murukutla S, Kohn N, Terjanian T and Widmann WD: Usefulness of the neutrophil-to-lymphocyte ratio in predicting short- and long-term mortality in breast cancer patients. Ann Surg Oncol 19: 217-224, 2012.

32. Movahedi K, Guilliams M, Van den Bossche J, Van den Bergh R, Gysemans C, Beschin A, De Baetselier P and Van Ginderachter JA: Identification of discrete tumor-induced myeloid-derived suppressor cell subpopulations with distinct T cell-suppressive activity. Blood 111: 4233-4244, 2008.

33. Youn JI, Nagaraj S, Collazo M and Gabrilovich DI: Subsets of myeloid-derived suppressor cells in tumor-bearing mice. J Immunol 181: 5791-5802, 2008.

34. Solito S, Marigo I, Pinton L, Damuzzo V, Mandruzzato S and Bronte V: Myeloid-derived suppressor cell heterogeneity in human cancers. Ann N Y Acad Sci 1319: 47-65, 2014.

35. Chen MF, Kuan FC, Yen TC, Lu MS, Lin PY, Chung YH, Chen WC and Lee KD: IL-6-stimulated CD11b ${ }^{+}$CD14 ${ }^{+}$ HLA-DR ${ }^{-}$myeloid-derived suppressor cells, are associated with progression and poor prognosis in squamous cell carcinoma of the esophagus. Oncotarget 5: 8716-8728, 2014.

36. Cuenca AG, Delano MJ, Kelly-Scumpia KM, Moreno C, Scumpia PO, Laface DM, Heyworth PG, Efron PA and Moldawer LL: A paradoxical role for myeloid-derived suppressor cells in sepsis and trauma. Mol Med 17: 281-292, 2011.

37. Dolcetti L, Peranzoni E, Ugel S, Marigo I, Fernandez Gomez A, Mesa C, Geilich M, Winkels G, Traggiai E, Casati A, et al: Hierarchy of immunosuppressive strength among myeloidderived suppressor cell subsets is determined by GM-CSF. Eur J Immunol 40: 22-35, 2010.

38. Haverkamp JM, Smith AM, Weinlich R, Dillon CP, Qualls JE, Neale G, Koss B, Kim Y, Bronte V, Herold MJ, et al: Myeloidderived suppressor activity is mediated by monocytic lineages maintained by continuous inhibition of extrinsic and intrinsic death pathways. Immunity 41: 947-959, 2014.

39. Umemura N, Saio M, Suwa T, Kitoh Y, Bai J, Nonaka K, Ouyang GF, Okada M,Balazs M, Adany R, et al: Tumor-infiltrating myeloid-derived suppressor cells are pleiotropic-inflamed monocytes/macrophages that bear M1- and M2-type characteristics. J Leukoc Biol 83: 1136-1144, 2008.

40. Sumida K, Wakita D, Narita Y, Masuko K, Terada S, Watanabe K, Satoh T, Kitamura H and Nishimura T: Anti-IL-6 receptor $\mathrm{mAb}$ eliminates myeloid-derived suppressor cells and inhibits tumor growth by enhancing T-cell responses. Eur J Immunol 42: 2060-2072, 2012.

41. Chen W, Jin W, Hardegen N, Lei KJ, Li L, Marinos N, McGrady G and Wahl SM: Conversion of peripheral $\mathrm{CD} 4^{+} \mathrm{CD} 25^{-}$naive $\mathrm{T}$ cells to $\mathrm{CD} 4{ }^{+} \mathrm{CD} 25^{+}$regulatory $\mathrm{T}$ cells by TGF-beta induction of transcription factor Foxp3. J Exp Med 198: 1875-1886, 2003.

(i) $(9)$ This work is licensed under a Creative Commons Attribution-NonCommercial-NoDerivatives 4.0 International (CC BY-NC-ND 4.0) License. 